\title{
Consideraciones sobre ensayos acelerados de resistencias de cemento
}

Prof. Dr. JOSE CALLEJA

\section{R E S U M E N}

Se pasa revista a los diversos métodos propuestos para la determinación de las resistencias de los cementos por procedimientos rápidos, así como a las características y circunstancias particulares de cada uno, haciendo destacar aquéllas que deben ser tenidas en cuenta en cualquier estudio o proyecto para establecer un método susceptible de ser normalizado o recomendado con validez internacional.

Acerca de los documentos presentados a la reunión anual de 1971 en Zurich, del Grupo de Estudios sobre Ensayos de Cemento y Hormigón del CEMBUREAU, en relación con el tema "Ensayo acelerado de cementos", se pueden hacer las consideraciones siguientes*:

\section{1) Respecto del tipo de material de ensayo}

El material que se ensaya puede ser:
a) pasta pura de cemento (1) (2);
b) mortero (2) (3) (4) (6);
c) hormigón.

\section{2) En cuanto al tipo de probeta ensayada}

Las probetas para el ensayo de la resistencia acelerada pueden ser:
a) mini-probetas (cubos, cilindros) (1) (2) (3) (6);
b) probetas de tamaño medio (cubos, prismas) (4);
c) probetas de gran tamaño (cilindros) (5).

\section{3) Con relación a la preparación (compactación) del material de las probetas}

La compactación de la pasta, mortero u hormigón (en cada caso) se puede hacer:

a) con presión aplicada en seco (1);

b) con presión aplicada en húmedo (2) (3) (6);

c) sin presión (4) (5).

Ampliación de una aportación hecha por el autor al citado Grupo de Estudio, en la mencionada reunión. 


\section{4) Con respecto al tipo de tratamiento preliminar (curado previo)}

El tratamiento preliminar o curado previo de las probetas de ensayo se puede efectuar:

a) a temperatura y humedad normales (2) (6);

b) bajo agua y a temperatura ordinaria (1);

c) a temperaturas más altas (3).

\section{5) En lo relativo al tipo de tratamiento (curado)}

El verdadero tratamiento o curado, acelerado o no, del material y probetas de ensayo puede realizarse:

a) bajo agua, a temperatura y humedad normales (1);

b) bajo agua caliente (4);

c) en autoclave (2) (3) (5) (6).

Por supuesto, existen otras posibilidades descritas en la bibliografía aportada por las mencionadas referencias (1) a (6), particularmente en lo que se refiere a los puntos 4) y 5); tales son, por ejemplo, el tratamiento preliminar y el curado en aire húmedo o en atmósfera de vapor a la presión ordinaria, etc.

Las condiciones experimentales determinan en cada caso el tiempo total de tratamiento y, por lo tanto, el tiempo transcurrido desde el amasado y enmoldado del material hasta el ensayo de rotura a compresión. Este tiempo varía, en general, entre 5 y 24 horas.

De lo que antecede cabe hacer destacar que las consideraciones 1) a 5), probablemente entre otras, habrán de ser tenidas en cuenta para decidir acerca de éllas en una discusión preliminar orientada a establecer un método común -internacional- de ensayo rápido de la resistencia de los cementos. Esto tiene una importancia particular si en la discusión se ha de incluir el tratamiento con vapor saturado a la presión atmosférica, ya que en tal caso deberán ser consideradas todas las múltiples variables implicadas, de acuerdo con las reglas bien conocidas y establecidas para este tipo de tratamiento (8) (9). Por ejemplo, un curado previo en condiciones normales a temperatura de unos $20^{\circ} \mathrm{C}$ y con una humedad relativa ambiental del orden de -o superior a- $95 \%$, anterior al tratamiento a $40^{\circ} \mathrm{C}$ durante 3 horas, tal vez podría dar lugar a resultados más fidedignos en el caso del ensayo según (3) y en general, dada la influencia de la duración y condiciones del período preliminar de fraguado normal espontáneo, en los efectos del tratamiento hidrotérmico.

En las consideraciones anteriores, y muy en particular en las 4) y 5), parece que debe tener una importancia capital el tipo - portland, siderúrgico, puzolánico, natural o aluminoso-, así como la clase - PAS, PHA, etc. - y la categoría o calidad -250, 350, 450— del cemento. Esto debe ser así, ya que no todos tienen el mismo esquema ni la misma cinética de fraguado y sobre todo de endurecimiento, ni, por lo tanto, son afectados de igual modo ni en igual medida por los diversos tratamientos térmicos acelerados.

En virtud de lo que precede, los ensayos acelerados de resistencia de cementos parecen, en principio y de momento, aplicables para el control rápido de la calidad de una producción de cemento dada, es decir, correspondiente a una fábrica o, mejor aún, a un horno determinado, en los que con un crudo y con un proceso, sensiblemente constantes, se produce clínker para cemento de un solo tipo y clase, con características en general poco variables entre límites estrechos, en particular las mecánico-resistentes. 
La extrapolación que supone pasar de este posible y probable campo de validez de los ensayos acelerados, a su utilización extensiva a cualquier clase de producción o de cemento, sobre todo con efectos comparativos, parece en principio arriesgada. En todo caso requeriría mucha experimentación.

En cuanto a los métodos de cálculo que basan la determinación rápida de las resistencias en la aplicación de múltiples coeficientes y ecuaciones de regresión (7), se podría objetar que tales métodos sólo son aplicables a cementos portland puros sin adiciones activas y no nocivas (escorias, puzolanas, cenizas volantes) o de cualquier tipo, si en dichas ecuaciones de regresión ha de entrar la composición potencial calculada, o la composición mineralógica determinada por técnicas de difracción de rayos $\mathrm{X}$.

Incluso en el caso de cementos sin ninguna adición cabría pensar lo mismo por lo que se refiere a la composición mineralógica determinada por difracción de rayos $\mathrm{X}$, dado que las fases intersticiales $\mathrm{C}_{3} \mathrm{~A}$ y $\mathrm{C}_{4} \mathrm{AF}$ se encuentran, al menos en parte, en forma microcristalina, pseudocristalina o incluso amorfa o vítrea a consecuencia del enfriamiento normalmente rápido o semi-rápido del clínker en los hornos de cemento, y dada la dificultad o imposibilidad de detección incluso cualitativa de estas fases por difractometría de rayos $\mathrm{X}$. Sin embargo, parece ser que, a pesar de esta posible objeción, los resultados prácticos demuestran que los comentados métodos de cálculo pueden ser aplicados con éxito (7).

No obstante, cabría pensar que las determinaciones microscópicas directas de los distintos constituyentes mineralógicos del cemento podrían ser valiosas, por cuanto permiten evaluar tanto las fases cristalinas como las intersticiales, vítreas, pseudocristalinas o microcristalinas del clínker y del cemento. De este modo los coeficientes de regresión para el $\mathrm{C}_{3} \mathrm{~A}$ y el $\mathrm{C}_{4} \mathrm{AF}$ podrían ser determinados con mayor precisión, obteniéndose así ecuaciones de regresión también más precisas. Es obvio, sin embargo, que una sola determinación microscópica es tal vez menos representativa que un difractograma de rayos $\mathrm{X}, \mathrm{y}$ que, incluida la preparación de las muestras, sobre todo si son de cemento, exige más trabajo y tiempo que una determinación difractométrica.

\section{R E F E R E N C I A S}

(1) Dalziel, J. A.; “A mini-cylinder test for the rapid determination of cement quality". Cement Technology 2 (4), 105-112 (1971).

(2) KEIL, F. and MATHIEU, H.: "Schnellprüfung von Zement nach dem Kleinzylinder-Verfahren". Zement-Kalk-Gips 17 (7), 279-298 (1964).

(3) Meyer, A.: "Prüfverfahren zur Vorausbestimmung der 28 Tage-Zement-Normendruckfestigkeit in Stunden". Zement-Kalk-Gips 18 (11), 574-579 (1965).

(4) “C.N.R.": (Centre National de Recherches Scientifiques et Techniques pour l'Industrie Cimentière -Belgique-): "Mode opératoire pour l'essai d'estimation rapide de la résistance des ciments". Decembre 1970.

(5) "LAFARGE": (Laboratoire Central); "Determination accélérée des résistances mécaniques des bétons". Ordre de Service n. ${ }^{\circ}$ 11.367-370, Avril 1971.

(6) "LOJO": (Lojo Kalkverk AB -Finland-): Circular letter 31, 17-8-1971, Ref. CH/MP. Véase referencia 2.

(7) Von Euv M. and Gourdin, P.: "Le calcul prévisionnel des résistances des ciments Portland". Matériaux et Constructions 3 (17), 299-310 (1970).

(8) SAUL, A.G.A.: "Principles underlaying the steam curing of concrete at atmospheric pressure". Magazine of Concrete Research, 127-40, marzo 1951.

(9) Calleja, J.: "Tratamientos térmicos del hormigón".

Revista de Ciencia Aplicada, Nos. 119 nov.-dic. 1967 y 120 ene.-feb. 1968 